\title{
Medullary Thyroid Carcinoma Associated with RET Mutations Located in Exon 8
}

\author{
Melpomeni Peppa ${ }^{1}$ and Sotirios A. Raptis ${ }^{2,3}$ \\ ${ }^{1}$ Endocrine Unit, Second Dept of Internal Medicine-Propaedeutic, \\ Research Institute and Diabetes Center, Athens University Medical School, \\ Attikon University Hospital, Athens \\ ${ }^{2}$ Second Dept of Internal Medicine-Propaedeutic, Research Institute and Diabetes Center, \\ Athens University Medical School, Attikon University Hospital, Athens \\ ${ }^{3}$ Hellenic National Diabetes Center for the Prevention, \\ Research and Treatment of Diabetes Mellitus and its Complications (H.N.D.C), Athens
}

Greece

\section{Introduction}

Medullary thyroid carcinoma is a neuroendocrine tumor which accounts for $5-10 \%$ of all thyroid cancers, with a various clinical course, being either an extremely benign tumor or an aggressive variant with a high mortality rate. Medullary thyroid carcinoma is sporadic in $80 \%$ of cases while in $20 \%$ of cases it follows a hereditary pattern, known as isolated familial MTC or multiple endocrine neoplasia type 2 syndromes, transmitted in an autosomaldominant manner. Genetic analysis of the RET protooncogene constitutes an excellent powerful diagnostic tool for medullary thyroid carcinoma, especially for the hereditary form. Somatic, germline but also de novo mutations have all been associated with sporadic and hereditary forms of the disease and exons 10,11,13-16 of the RET gene locus are mainly involved. However, accumulating data support the association of other exons, including exon 8, with MTC but more studies need to be done, in order to provide more information about its role on the disease start, progression, potential and penetrance. At present, a "complete" germline RET testing should be performed in all MTC patients, independently of the family history and especially in the case of a negative testing, should include "non classical" exons, including exon 8.

\section{Medullary thyroid carcinoma}

Medullary thyroid carcinoma (MTC) is a neuroendocrine tumor which originates from the parafolicular C-cells of the thyroid gland, accounting for $5-10 \%$ of all thyroid cancers. (Pacini, 2010, Alevizaki 2006, Leboulleux 2004) Nowadays, the rate of MTC diagnosis gradually increases due to high awareness and thus careful investigation. MTC is a multifacet disease being either an extremely benign tumor or an aggressive variant which is associated with a high mortality rate because of lack of appropriate therapeutic regimens. (Pacini, 2010, Alevizaki 2006, Leboulleux 2004, Roman 2006) 
MTC, is sporadic in $80 \%$ of cases (SMTC), presenting as an asymptomatic, accidentally found neck mass in the middle age, which spreads to regional lymph nodes in up to $50 \%$ of cases, as well as to distant sites (mediastinum, liver, lungs,bone). (Moo-Young 2009, Raue 2010, Alevizaki 2009) However, in 7\% of individuals with apparently sporadic tumors, genetic screening revealed germline mutations of the RET (REarranged during Transfection) protooncogene $(R E T)$, indicating an overdiagnosis of SMTC in the absence of genetic screening. (Elisei 2007, Romei 2011).

In $20 \%$ of cases, MTC follows a hereditary pattern (HMTC), known as isolated familial (FMTC) or multiple endocrine neoplasia type 2 (MEN2) syndromes, transmitted in an autosomal-dominant manner. (Moo-Young 2009, Raue 2010, Alevizaki 2009) In opposite to the sporadic form, HMTC is characterized by small, frequently multifocal and bilateral nodules. (Moo-Young 2009, Raue 2010, Alevizaki 2009) The earlier identification of kindreds at risk of HMTC and the earlier selection of affected members for prophylactic thyroidectomy (14.9 versus 36.4 years), has resulted in a decrease in primary tumor size from 0.8 to $0.2 \mathrm{~cm}$, a reduction in the percentage of bilateral neoplasms from $100 \%$ to $13 \%$, a fall in the rate of lymph node metastases from $58 \%$ to $0 \%$, all of them associated with less morbidity and mortality from HMTC. (Wells 1994, Graze 1978, Lips 1994)

FMTC, accounts for $35-40 \%$ of HMTC, exhibits variable expressivity and penetrance and follows a more indolent course compared to MEN syndromes, with a late onset or no clinically manifest disease and relative good prognosis. (Moo-Young 2009, Raue 2010, Alevizaki 2009) However, the diagnosis of MTC as FMTC is not sometimes correct. MTC is often the first manifestation of MEN2A, misclassified as FMTC with pheochromocytomas diagnosed later while a significant overlap in the genetic mutations between FMTC and MEN2A is observed. (Moo-Young 2009, Raue 2010, Alevizaki 2009) Thus, the definition of FMTC is strict and needs multiple members affected after the age of 50 years and the absence of either pheochromocytoma or hyperparathyroidism in more than 10 carriers. (Brandi 2001) Nowadays, FMTC is considered as a phenotypic mildest variant of MEN2A, in which there is a strong predisposition to MTC and decreased penetrance of pheochromocytoma and primary hyperparathyroidism. In practical terms, especially in smaller kindreds, it is suggested that it is safer to label a family as MEN2A than FMTC, which ensures that patients are screened and monitored for the development of pheochromocytomas. (Moo-Young 2009, Raue 2010, Alevizaki 2009, Brandi 2001)

MEN2, is a rare cancer syndrome, transmitted in an autosomal dominant manner. The estimated prevalence is 2.5 per 100,000 cases in the general population. More than 1,000 kindreds have been described while many others have never been reported. MEN2 syndromes, involve MTC, following by pheochromocytoma in $50 \%$ of cases, primary hyperparathyroidism in $30 \%$ of cases and less commonly other clinical manifestations such as cutaneous lichen amyloidosis or Hirschsprung's disease. (Moo-Young 2009, Raue 2010, Alevizaki 2009)

MEN2A, accounts for 55\% of all cases with MEN2, consisting of MTC in 75\% - $90 \%$ of cases, in combination with pheochromocytoma and primary hyperparathyroidism. MTC is typically multifocal and bilateral, starts in early adulthood and is responsible for most of the mortality associated with MEN2A, indicating the need for early recognition and treatment. (Moo-Young 2009, Raue 2010, Alevizaki 2009)

MEN2B syndrome, accounts for $5-10 \%$ of cases with MEN2, consisting of MTC, pheochromocytoma (50\%), ganglioneuromatosis, Marfanoid habitus and less often clinical 
manifestations (megacolon, skeletal abnormalities, markedly enlarged peripheral nerves). MTC has its onset at a very young age (infancy), is most commonly aggressive and the patients are rarely cured of their disease, due to delayed diagnosis. (Moo-Young 2009, Raue 2010, Alevizaki 2009)

\section{Diagnosis of medullary thyroid carcinoma}

Since MTC is a multifacet thyroid cancer with a benign or aggressive course, the early recognition and treatment, even at the preclinical stage, is of crucial importance, leading in a higher cure rate of affected patients and a much better prognosis. (Roman 2006, Wells 1994, Graze 1978).

During the last decade, a great progress in the diagnostic identification of MTC has been made. Although questionable, calcitonin screening in patients with thyroid nodules has led to an increased rate of MTC diagnosis. Traditionally, calcitonin levels either basal or after provocative testing, constitute important diagnostic tools, in the identification of patients harbouring MTC. (Lips 1994) However, since the late 1990s, with the advent of molecular biology, genetic analysis of the RET, has been proved as a powerful diagnostic tool for MTC, especially HMTC . (Brandi 2001, Kouvaraki 2005)

\section{Genetics of medullary thyroid carcinoma}

MTC has been associated with mutations in the RET, a 21 exons gene, mapped to chromosome 10q11.2. (Brandi 2001, Kouvaraki 2005, Arighi 2005, Plaza-Menacho 2006) RET is a receptor tyrosine kinase, which exhibits trans-autophosphorylation of intracellular tyrosine residues and activation of downstream signaling pathways (Ras/ERK, phosphotidylinositol-3-kinase/AKT, beta-catenin/WNT, phospholipase, C gamma, Src), in tissues that express the receptor. The RET protein consists of a $\mathrm{N}$ terminal signal peptide, an extracellular region with 4 cadherin-like repeats, a calcium- binding site and a cysteine-rich domain, a transmembrane region, and an intracellular portion with two tyrosine kinase domains.(Kouvaraki 2005, Arighi 2005, Plaza-Menacho 2006) Activating point mutations in RET lead to constitutive activity of the receptor, C-cell hyperplasia $(\mathrm{CCH})$ and MTC. The scenario of the "two hits" is now supported, including an inherited "first hit" leading to C-cell hyperplasia and a secondary somatic "second hit" in activated C cells, leading to HMTC. (Roman 2006) Genetic analysis of RET diagnoses MTC in about 98\% of known families. (Brandi 2001) Since the distinction between sporadic and hereditary forms of MTC is not often clear, nowadays, RET molecular testing has solved a lot of diagnostic problems in patients with MTC, ensuring a better management of patients and their families and less MTC associated morbidity and mortality. (Wells 1994, Graze 1978, Lips 1994)

\subsection{RET mutations}

Since 1993, that the first germline mutation of the RET was identified, an accumulating number of RET mutations has been isolated, linked to MTC. (Brandi 2001, Kouvaraki 2005, Arighi 2005, Plaza-Menacho2006) Based on the RET molecular testing, 1-7\% of cases with apparently sporadic tumors were found to have RET mutations. (Elisei 2007, Romei 2011, Wohllk 1996, Blaugrund 1994, Elisei 2008) 
Genetic testing of the RET is performed by PCR amplification of the patient's germline DNA obtained from white blood cells or thyroid tissue. Initially, exons 10, 11, 13, 14, 15, and 16 are carefully screened and if no mutations are detected, the remaining 15 exons of the RET gene should be sequenced. It has been estimated that mutations are found in over $95 \%$ of cases of HMTC. Otherwords, the predicted risk of HMTC in a patient with a negative genetic testing is estimated to be only $0.18 \%$. (Kouvaraki 2005)

The RET mutations might occur: in the substrate recognition pocket of the catalytic core (mutations in codon 918), leading to receptor dimerization and cross-phosphorylation; in the extracellular domain (exons 8, 10,11) leading to ligand-independent homodimerization, cross-phosphorylation and receptor activation; in the intracellular domain (exons 13, 14, 15, 16), leading to alteration in the substrate recognition pocket of the catalytic core with constitutive activation of the RET kinase enzyme catalytic site and autophosphorylation. RET mutations in MEN2 are typically missense mutations that lead to ligand independent receptor activation, a model that is well known for a variety of human cancers, but is uncommon for a hereditary cancer gene. (Kouvaraki 2005, Arighi 2005, Plaza-Menacho2006) The identified RET mutations exhibit a strong genotype-phenotype correlation and they are classified into 3 groups with a 14-fold incremental increase from mutations in level 1 to level 3. (Kouvaraki 2005, Donis-Keller 1993, Eng 1996, Alevizaki 1997, Yip 2003, Marx 2005, Mulligan 1993, Machens 2003) Recent guidelines from the American Thyroid Association (ATA) propose a classification of RET mutations in 4 levels (A-D), with level D mutations denoting the highest risk for early onset or aggressive MTC and level A mutations carrying the lowest risk. (Kloos 2009).

\subsection{RET mutations and sporadic medullary thyroid cancer}

Approximately $50-60 \%$ of specimens from patients with SMTC, contain somatic but not germline RET mutations. (Wohllk 1996, Blaugrund 1994, Elisei 2008) The most common somatic mutations occur in codons 918 and 833 (exons 15 and 16) while less commonly somatic mutations in exons 10 and 11 are found which are associated with poor prognosis (Wohllk 1996, Blaugrund 1994, Elisei 2008) Murra et al, has demonstrated somatic mutations in 64.7\% of MTC tumours. Exon 16 was the most frequently affected $(60.6 \%)$, followed by exon 15 , while exons 5,8,10-14, were less affected. Mutations in exons 15 and 16, were associated with higher prevalence of persistent, multifocal MTC with a spread in regional lymph nodes, while mutations in exons 5,8,10-14, were associated with the most indolent course of MTC. (Moura 2009) Schilling et al, examined multiple lymph nodes from patients with SMTC and demonstrated that $76 \%$ of patients with SMTC had concordant codon-918 mutation in all lymph nodes tested (43\% all positive, 33\% all negative). Moreover, patients with somatic codon-918 mutations had an increased rate of metastases to distant sites (lung, bone, liver) and an overall worst prognosis. (Schilling 2001 A single nucleotide polymorphism (SNP) of RET, G961S, has been shown to be more frequent in patients with SMTC compared with healthy subjects, associated with an earlier age of MTC, and with higher calcitonin levels. (CardotBauters 2008, Robledo 2003, Elisei 2004). The real significance of the observed mutations is not clear. The coexistence of mutation positive and negative regions in MTC tumors, suggests that these mutations may not always be initiating or essential. (Eng 1996)

At present, genetic testing for tumor mutations of the RET is not part of the routine practice in patients with SMTC, as the clinical utility is still undefined. However, screening of individuals with apparently sporadic MTC may uncover germline RET mutations in approximately $7 \%$ of 
cases, which in about 2-9\% are de novo mutations, suggesting that these cases had actually HMTC and not SMTC. (Elisei 2007, Romei 2011, Wohllk 1996, Blaugrund 1994, Elisei 2008) In addition, the existing clinical data suggest a correlation of the RET mutations with the course of the disease and possibly the response to treatment which is going to be further evaluated by clinical trials which are in progress. Thus, it might be useful to perform RET genetic testing in all patients with MTC, even in those with apparently SMTC.

\subsection{RET mutations and hereditary medullary thyroid cancer}

To date, $98 \%$ of affected families with HMTC apparently exhibit genetic linkage to the RET gene locus and only a small percentage of MEN2 families have had no RET mutation detected. (Kouvaraki 2005, Donis-Keller 1993, Eng 1996, Alevizaki 1997, Yip 2003, Marx 2005, Mulligan 1993 )

Isolated FMTC has been traditionally associated with germline-activating mutations of the extracellular region of RET, mainly at cysteine codons $609,611,618,620,630,634$ in exons 10 and 11, in the extracellular domain which is associated with the three-dimensional ligandbinding pocket. These mutations lead to ligand-independent dimerization and receptor activation. Noncysteine mutations of the intracellular region of RET in exons 13-16 are less commonly linked to FMTC while mutations in other exons have been rarely reported in isolated families. Some mutations (particularly codons 532, 533, 630, 769, V804M, 844, 912) are thought to be relatively specific for FMTC. However, codon 533 is also associated with MEN2A, indicating that only time and observation in large numbers of families can confirm this specificity. (Kouvaraki 2005, Peppa 2008, Kamakari 2008) Nowadays, FMTC constitutes a challenging form of MTC, which is considered as a phenotypic mildest variant of MEN2A. A number of FMTC patients finally have MEN2A while a significant overlap in the observed RET mutations, is commonly found.

Different RET mutations lead to the distinct clinical syndromes of MEN2A, MEN2B, and FMTC while a significant overlap exists between RET mutations associated with FMTC or MEN2A. The great majority of patients with MEN2A have mutations of RET in exons 10,11,13-16 while patients with MEN2B exhibit a single mutation at codon 918 of exon 16. (Kouvaraki 2005, Donis-Keller 1993, Eng 1996, Alevizaki 1997, Yip 2003, Marx 2005, Mulligan 1993, Hofstra 1994 )

Due to a strong genotype-phenotype correlation in MTC, the genetic analysis and the identification of specific germline RET mutations offer important information regarding the penetrance of MTC and associated lesions. For example, mutations at codon 634 in exon 11 accounts for approximately $60 \%$ of all MEN2 families rather than FMTC, with hyperparathyroidism occurring in $20 \%$ of patients, a manifestation which is uncommon with other RET mutations. (Schuffenecker 1998, Karga 1998) In addition, the same mutations are associated with significantly earlier progression from C-cell hyperplasia to MTC and earlier lymph node involvement than patients with most other mutations related to MEN2A and FMTC. (Peppa 2008, Hofstra 1994) According to the International RET Exon 10 Consortium, codon-associated penetrance by age 50, ranged from $60 \%$ (codon 611) to $86 \%$ (620) while more advanced stage and increasing risk of metastases correlated with mutation in codon position $(609 \rightarrow 620)$ near the juxtamembrane domain. (Frank-Raue 2011) A large European consortium study reported by Machens et al, offer detailed clinical penetrance data, analyzed according to individual mutations. (Machens 2003) 


\subsection{De novo RET mutations and hereditary medullary thyroid carcinoma}

A small percentage (3-6\%), of patients with MTC, have a negative family history and germline RET mutations which arise de novo. Such de novo mutations are noted at a much higher frequency in the allele inherited from the patient's father. (Wohllk 1996, DonisKeller 1993, Eng 1996, Alevizaki 1997, Carlson 1994) Unlike MEN2A, MEN2B is commonly associated with de novo germline mutations and the diagnosis is most often based on the characteristic clinical features (elongated facies, oral ganglioneuromas of the lips and tongue). Such de novo mutation at codon 883 in exon 15, has been found in a small number of MEN2B families. (Gimm 1997) Because of frequent de novo mutations, patients with MEN2B should be suspected on the basis of the characteristic features and not on the family history. De novo RET mutations, tend to be disproportionately clustered in the intracellular domain (exons 13-15), linked with reduced MTC penetrance, compared to the more classic familial patterns associated with extracellular mutations in exons 10 and 11.

\subsection{RET mutations in exon 8 and hereditary medullary thyroid carcinoma}

In addition to the classical RET mutations observed in exons 10,11,13-16, accumulating data support the association of RET mutations in other exons associated with HMTC, including exon 8 . The first report by Pigny et al. described a 9 bp duplication of exon 8 in a family with FMTC. (Pigny 1999) Da Silva et al, in a study of 76 patients with FMTC from a 6-generation Brazilian family with 229 subjects, demonstrated a new missense point RET mutation in exon 8 (1597G-->T) corresponding to a Gly(533)Cys substitution in the cysteine-rich domain. (Da Silva 2003) Kaldrymides et al, detected the same mutation in all seven FMTC Greek patients and in 13 heterozygotes and 1 homozygote asymptomatic relatives, with a wide clinical heterogenecity. (Kaldrymides 2006) Fazioli et al, found 4 novel RET variants, located in the extracellular domain (p.A510V, p.E511K and p.C531R) coded by exon 8 on the leukocyte DNA from apparently sporadic cases, in addition to the intracellular juxtamembrane region (. $\mathrm{K} 666 \mathrm{~N})$ coded by exon 11, suggesting that these variants are associated with FMTC. (Fazioli 2008) Peppa et al, found the same mutation, in 2 index patients with MEN2A, consisting of pheochromocytoma and MTC and in 6 out of $12(50 \%)$ family members. Additionally, one of the index patients was asymptomatic, the pheochromocytoma being accidentally found, while the second patient had hypertension but negative testing for pheochromocytoma despite repeated measurements. Furthermore, the MTC was least aggressive as it was not clinically apparent, while none of the family members died from MTC-related causes. (Peppa 2008) Moreover, Kamakari et al, have identified the same G533C mutation in 11 unrelated families with FMTC and 4 with MEN2A, explaining the 'RET-negative' FMTC/MEN2A patients. (Kamakari 2008). The above observations are considered quite interesting points in the characterization of the MEN2A phenotype associated with the G533C point mutation in exon 8 of the RET which seems to be less aggressive. The existing data, reveal an oncogenic potential for all the novel germline RET variants, including exon 8 genomic variations, which seem to have a higher oncogenic potential than previously thought. (Muzza 2010)

The above findings indicate that patients with MTC should be screened for other components of MEN and also should be evaluated through a complete genetic screening including exon 8, especially if the classical RET screening is negative. 


\section{Conclusion}

RET molecular testing has offered tremendous help on the early identification of patients with MTC, the distinction between the sporadic and hereditary forms of MTC, the prognosis of the natural course of the disease and the response to treatment. To date, the identified RET mutations exhibit a strong genotype-phenotype correlation, which has been the basis for establishing the clinical risk levels depending on the nature of the mutations. A "complete" germline RET testing should be performed in all MTC patients, independently of the family history, including 10,11, 13-16 and other " non classical" exons including exon 8 , especially in the case of a negative testing. At present, the risk profiles and the penetrance estimations cannot be done in patients with MTC of all causes, caused by RET mutations in exon 8 , due to the deteriorated data. More studies need to be done, in order to provide more information about the role of exon 8 genomic variations, on the disease start, progression, potential and penetrance.

\section{References}

[1] Alevizaki M. Medullary thyroid carcinoma: clinical presentation and diagnosis. In Thyroid Cancer, Thessaloniki,2006; pp 395-411. Ed.Hercules Vainas.

[2] Alevizaki M, Stratakis CA. Multiple endocrine neoplasias: advances and challenges for the future. J Intern Med. 2009;266(1):1-4.

[3] Alevizaki M, Sarika H, Koutras DA, Souvatzoglou A. Genetic screening for RET mutations in families with multiple endocrine neoplasia 2 syndromes. Ann N Y Acad Sci. 1997;816:383-8.

[4] Arighi E, Borrello MG, Sariola H. RET tyrosine kinase signaling in development and cancer. Cytok Growth Factor Rev 2005; 16(4-5):441-467

[5] Blaugrund JE, Johns MM Jr, Eby YJ, et al. RET proto-oncogene mutations in inherited and sporadic medullary thyroid cancer. Hum Mol Genet 1994; 3:1895-1897.

[6] Brandi ML, Gagel RF, Angeli A, et al. Guidelines for diagnosis and therapy of MEN type 1 and type 2. J Clin Endocrinol Metab 2001; 86:5658-5671.

[7] Cardot-Bauters C, Leteurtre E, Leclerc L, et al. Does the RET variant G691S influence the features of sporadic medullary thyroid carcinoma? Clin Endocrinol (Oxf) 2008; 69(3):506-510

[8] Carlson KM, Bracamontes J, Jackson CE, et al. Parent-of-origin effects in multiple endocrine neoplasia type 2B. Am J Hum Genet 1994; 5:1076-1082.

[9] Da Silva AM, Maciel RM, Da Silva MR, Toledo SR, De Carvalho MB, Cerutti JM. A novel germ-line point mutation in RET exon 8 (Gly(533)Cys) in a large kindred with familial medullary thyroid carcinoma. J Clin Endocrinol Metab. 2003; 88(11):543843.37.

[10] Donis-Keller H, Dou S, Chi D, et al. Mutations in the RET protooncogene are associated with MEN 2A and FMTC. Human Molecular Genetics 1993;2 851-856.

[11] Elisei R, Romei C, Cosci B, et al. RET genetic screening in patients with medullary thyroid cancer and their relatives: experience with 807 individuals at one center. $\mathrm{J}$ Clin Endocrinol Metab 2007; 92(12):4725-4729 
[12] Elisei R, Cosci B, Romei C, et al. Prognostic significance of somatic RET oncogene mutations in sporadic medullary thyroid cancer: a 10-year follow-up study. J Clin Endocrinol Metab 2008; 93(3):682-687

[13] Elisei R, Cosci B, Romei C, et al. RET exon 11 (G691S) polymorphism is significantly more frequent in sporadic medullary thyroid carcinoma than in the general population. J Clin Endocrinol Metab 2004; 89(7):3579-3584

[14] Eng C, Clayton D, Schuffenecker I, et al. The relationship between specific RET protooncogene mutations and disease phenotype in multiple endocrine neoplasia type 2: International RET Mutation Consortium analysis. J Am Med Assoc 1996; 276:15751579 .

[15] Eng C, Mulligan LM, Healey CS, et al. Heterogeneous mutation of the RET protooncogene in subpopulations of medullary thyroid carcinoma. Cancer Res 1996; 56:2167-2170.

[16] Fazioli F, Piccinini G, Appolloni G, et al. A new germline point mutation in Ret exon 8 (cys515ser) in a family with medullary thyroid carcinoma. Thyroid. 2008;18(7):77582.

[17] Frank-Raue K, Rybicki LA, Erlic Z, et al. International RET Exon 10 Consortium. Risk profiles and penetrance estimations in multiple endocrine neoplasia type $2 \mathrm{~A}$ caused by germline RET mutations located in exon 10.Hum Mutat. 2011;32(1):51-8.

[18] Gimm O, Marsh DJ, Andrew SD, et al. Germline dinucleotide mutation in codon 883 of the RET proto-oncogene in multiple endocrine neoplasia type $2 \mathrm{~B}$ without codon 918 mutation. J Clin Endocrinol Metab 1997; 82:3902-3904.

[19] Graze K, Spiler IJ, Tashjian AH, et al. Natural history of familial medullary thyroid carcinoma. Effect of a program for early diagnosis. N Engl J Med 1978; 299:980-985.

[20] Hofstra RM, Landsvater RM, Ceccherini I, et al. A mutation in the RET proto-oncogene associated with multiple endocrine neoplasia type $2 \mathrm{~B}$ and sporadic medullary thyroid carcinoma. Nature 1994;367:375-376.

[21] Kaldrymides P, Mytakidis N, Anagnostopoulos T, et al. A rare RET gene exon 8 mutation is found in two Greek kindreds with familial medullary thyroid carcinoma: implications for screening. Clin Endocrinol (Oxf). 2006 ; 64(5):561-6.

[22] Kamakari S, Alevizaki M, Bei T, et al. The rare mutation of RET gene G533C is found in 15 unrelated Greek families explaining the 'RET-negative' patients FMTC/MEN2A.(Abstract). Hormones 2008;7 (Suppl 2):70.

[23] Karga HJ, Karayianni MK, Linos DA, Tseleni SC, Karaiskos KD, Papapetrou PD. Germ line mutation analysis in families with multiple endocrine neoplasia type $2 \mathrm{~A}$ or familial medullary thyroid carcinoma. Eur J Endocrinol. 1998;139(4):410-5. 25.26. 30.31.

[24] Kloos RT, Eng C, Evans DB, et al. Medullary thyroid cancer: management guidelines of the American Thyroid Association. Thyroid 2009; 19(6):565-612

[25] Kouvaraki MA, Shapiro SE, Perrier ND, et al. RET proto-oncogene: A review and update of genotype-phenotype correlations in hereditary medullary thyroid cancer and associated endocrine tumors. Thyroid 2005; 15:531-544.

[26] Leboulleux S, Baudin E, Travagli JP, Schlumberger M. Medullary thyroid carcinoma. Clin Endocrinol (Oxf). 2004;61:299-310. 
[27] Lips CJM, Landsvater RM, Hoppener JWM, et al. Clinical screening as compared with DNA analysis in families with multiple endocrine neoplasia type 2A. N Engl J Med 1994;331:828-835.

[28] Machens A, Niccoli-Sire P, Hoegel J, et al. Early malignant progression of hereditary medullary thyroid cancer. N Engl J Med. 2003; 349: 1517-1525.

[29] Marx SJ. Molecular genetics of multiple endocrine neoplasia types 1 and 2. Nat Rev Cancer 2005; 5(5):367-375

[30] Moo-Young TA, Traugott AL, Moley JF. Sporadic and familial medullary thyroid carcinoma: state of the art. Surg Clin North Am. 2009;89(5):1193-204.

[31] Moura MM, Cavaco BM, Pinto AE, et al. Correlation of RET somatic mutations with clinicopathological features in sporadic medullary thyroid carcinomas. Br J Cancer 2009; 100(11):1777-1783

[32] Mulligan LM, Kwok JB, Healey CS, et al. Germ-line mutations of the RET protooncogene in multiple endocrine neoplasia type 2A. Nature 1993; 363 458-460.

[33] Muzza M, Cordella D, Bombled J, et al. Four novel RET germline variants in exons 8 and 11 display an oncogenic potential in vitro. Eur J Endocrinol. 2010; 162(4):771-7.

[34] Pacini F, Castagna MG, Cipri C, Schlumberger M. Medullary thyroid carcinoma. Clin Oncol (R Coll Radiol). 2010; 22(6):475-85.

[35] Peppa M, Boutati E, Kamakari S, et al. Multiple endocrine neoplasia type 2A in two families with the familial medullary thyroid carcinoma associated G533C mutation of the RET proto-oncogene. Eur J Endocrinol. 2008;159(6):767-71.

[36] Pigny P, Bauters C, Wemeau JL, et al. A novel 9-base pair duplication in RET exon 8 in familial medullary thyroid carcinoma. J Clin Endocrinol Metab 1999; 84:1700-1704

[37] Plaza-Menacho I, Burzynski GM, de Groot JW, Eggen BJ \& Hofstra RM. Current concepts in RET-related genetics, signaling and therapeutics. Trends in Genetics 2006; 22 627-636.

[38] Raue F, Frank-Raue K. Update multiple endocrine neoplasia type 2. Familial Cancer 2010; 9:449-457

[39] Robledo M, Gil L, Pollán M, et al. Polymorphisms G691S/S904S of RET as genetic modifiers of MEN 2A. 2003; Cancer Res 63(8):1814-1817

[40] Roman S, Lin R, Sosa JA. Prognosis of medullary thyroid carcinoma: demographic, clinical, and pathologic predictors of survival in 1252 cases. Cancer. 2006;107(9):2134-42.

[41] Romei C, Cosci B, Renzini G, et al. RET genetic screening of sporadic medullary thyroid cancer (MTC) allows the preclinical diagnosis of unsuspected gene carriers and the identification of a relevant percentage of hidden familial MTC (FMTC). Clin Endocrinol (Oxf). 2011;74(2):241-7.

[42] Schilling T, Bürck J, Sinn HP, et al. Prognostic value of codon 918 (ATG-->ACG) RET proto-oncogene mutations in sporadic medullary thyroid carcinoma. Int J Cancer. 2001; 95(1):62-6.

[43] Schuffenecker I, Virally-Monod M, Brohet R, et al. Risk and penetrance of primary hyperparathyroidism in multiple endocrine neoplasia type $2 \mathrm{~A}$ families with mutations at codon 634 of the RET proto-oncogene. J Clin Endocrinol Metab 1998; 83:487-491. 
[44] Wells SA, Chi DD, Toshima K, et al. Predictive DNA testing and prophylactic thyroidectomy in patients at risk for multiple endocrine neoplasia type 2A. Ann Surg 1994;220:237-250.

[45] Wohllk N, Cote GJ, Bugalho MM, et al. Relevance of RET protooncogene mutations in sporadic medullary thyroid carcinoma. J Clin Endocrinol Metab 1996; 81:3740-3745.

[46] Yip L, Cote GJ, Shapiro SE, et al. Multiple endocrine neoplasia type 2: evaluation of the genotype-phenotype relationship. Arch Surg 2003; 138 (4):409-416 


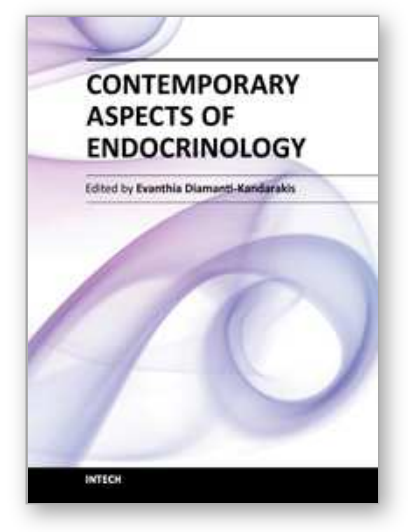

\author{
Contemporary Aspects of Endocrinology \\ Edited by Dr. Evanthia Diamanti-Kandarakis
}

ISBN 978-953-307-357-6

Hard cover, 454 pages

Publisher InTech

Published online 30, November, 2011

Published in print edition November, 2011

This book aims to provide readers with a general as well as an advanced overview of the key trends in endocrine disorders. While covering a variety of topics ranging from thyroid carcinogenesis and pituitary adenomas to adrenal tumors and metabolic bone disease, this book also focuses on more specific issues not yet fully elucidated (e.g. the molecular pathways involved in thyrotropin beta gene regulation or monogenic phosphate balance disorders). Readers of different fields and background will have the opportunity to update their knowledge and more importantly to clarify areas of uncertainty and controversies in several topics of endocrine disorders.

\title{
How to reference
}

In order to correctly reference this scholarly work, feel free to copy and paste the following:

Melpomeni Peppa and Sotirios A. Raptis (2011). Medullary Thyroid Carcinoma Associated with RET Mutations Located in Exon 8, Contemporary Aspects of Endocrinology, Dr. Evanthia Diamanti-Kandarakis (Ed.), ISBN: 978-953-307-357-6, InTech, Available from: http://www.intechopen.com/books/contemporary-aspects-ofendocrinology/medullary-thyroid-carcinoma-associated-with-ret-mutations-located-in-exon-8

\section{INTECH}

open science | open minds

\section{InTech Europe}

University Campus STeP Ri Slavka Krautzeka 83/A 51000 Rijeka, Croatia Phone: +385 (51) 770447

Fax: +385 (51) 686166 www.intechopen.com

\section{InTech China}

Unit 405, Office Block, Hotel Equatorial Shanghai No.65, Yan An Road (West), Shanghai, 200040, China 中国上海市延安西路65号上海国际贵都大饭店办公楼405单元 Phone: +86-21-62489820

Fax: $+86-21-62489821$ 
(C) 2011 The Author(s). Licensee IntechOpen. This is an open access article distributed under the terms of the Creative Commons Attribution 3.0 License, which permits unrestricted use, distribution, and reproduction in any medium, provided the original work is properly cited. 